\title{
Recognizing Lifelong Learning via Credit Systems - Strategies and Practices of Selected European Countries
}

\author{
Silvia Annen, Christiane Eberhardt \\ Federal Institute for Vocational Education and Training
}

\begin{abstract}
In general credit systems are supposed to facilitate transparency, comparability, transferability and mutual recognition of proved learning outcomes and to contribute to a better permeability of the educational system. It is peculiar that within the pan-European initiatives towards the implementation of credit systems the central elements are the awarding of credits and the accumulation of certified learning outcomes on the basis of modular structured units of qualification. Regardless of these central elements the core of a credit system lies within facilitating access and transmission between different learning contexts and shortening the duration of training. Therefor the crucial questions of this paper are if in selected countries already approaches and models exist, which also aim to facilitate transparency, comparability and recognition and on which central elements they are based. Relevant examples, which are implemented respectively discussed, can be found in Germany, Denmark, the Netherlands and Scotland.
\end{abstract}

\section{Introduction}

On the European political agenda the credit system for vocational education and training (ECVET) can be regarded as one of the most important instruments to facilitate transparency and mutual recognition of learning outcomes between different learning institutions, whether in the same country or abroad. Qualifications at all levels of the European qualifications framework (EQF) are covered by ECVET. So this instrument necessarily has to be used as a European reference point to which the national systems and approaches are compared and put into a relation [1: 1].

The implementation process of ECVET started in 2009 with the adoption of the Recommendation by the European Parliament and the Council. The testing and development of the system as well as the creation of national conditions for the implementation of the system mainly took place within pilot projects and networks in different contexts and systems on a European, a national as well as a sectoral level. In 2012 the Member States are expected to have created the necessary conditions and measures for the gradual implementation of ECVET. Finally in 2014 the European Parliament and the Council will review and evaluate the first stage of the ECVET implementation process [2]. Figure 1 illustrates this progressive process.

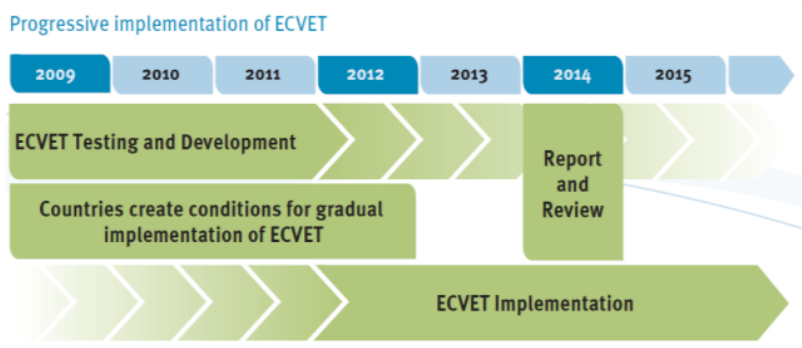

Source: Education and Culture DG, n.d.

Figure 1. Implementation process of ECVET

Within the European definition credit systems "enable accumulation of learning outcomes gained in formal, non-formal and/or informal settings, and facilitate their transfer from one setting to another for validation and recognition" [3: 53]. The understanding of 'credit systems' within the presented project is broader than the common understanding of this term, because the approaches in the respective countries except Scotland - are practised without granting credit points. Although in every analysed country an institutional and legal framework exists, which enables the recognition of learning outcomes, the knowledge about the concrete practice and implementation, the de facto use and the impact of these approaches and models is insufficient. Furthermore it is to question whether the implemented approaches can be understood as a comprehensive system over all different learning contexts of the educational system, which is able to facilitate the transparency, comparability, transferability and mutual recognition 
of proved learning outcomes as well as to promote lifelong learning and permeability. The core of the project was a deepened analysis of approaches and if applicable systems or procedures, which are used within the different countries to describe, evaluate/control, document and to recognize prior learning. Furthermore within the project it was investigated, how these approaches are realized in practice and which effects they have at the selected interfaces within the system.

In the focus of the research process are questions regarding the reason for special phenomena (institutional circumstances and conditions of the educational system) as well as questions regarding the social process, within which the mechanisms operate (driving forces and methodological-conceptual fundamentals). The project was constructed as an explorative study, which wanted to reconstruct influencing factors, transfer processes and impact mechanisms of credit systems respectively recognition approaches, that is identify the causal mechanisms within systems of interaction and within stakeholder constellations. Furthermore the project aims to propose options and regulative needs for the development of national credit system.

To theoretically conceptualise and analyse the processes in the context of recognition and crediting of prior learning an institutional research perspective is required. So to examine recognition and credit systems not only pedagogical theories but especially institutional theoretical approaches are relevant and were explored within the study. Besides the competence theory and the certification theory the theoretical basis of the analysis is formed by the institution theory and the governance approach.

\section{Methodology}

The project 'Credit Systems for Lifelong Learning' follows a qualitative research approach. Documents and data from the four selected countries (Germany, Denmark, the Netherlands and Scotland) are analysed and evaluated. The results of this first research phase, which was dominated by a hermeneutic approximation towards the methodological-conceptual fundamentals and the institutional circumstances of recognition approaches, are four country studies. They reflect the status quo of recognition respectively credit systems within the selected countries and give an overview of the used approaches in practice. The result of this research phase provides an inventory and a systematization of national approaches.

This overview was deepened within a further step by expert interviews in the fields of policy, practice, administration and research. These interviews were conducted to identify social mechanisms and to discover the real use of the recognition approaches as well as their benefit and impact at the defined interfaces 'access to the qualification system' and 'transfer between qualification systems' from the interviewees' point of view.

Between the participating countries common interview modules were coordinated, which were addressed as issues within the expert interviews. The interview guideline, which was adjusted towards the national specifics, includes the following aspects: terminology, procedures, operation and lifelong learning. Furthermore within the interviews core aspects of interest were the following: driving forces, expectations regarding ECVET, perspectives/connection with lifelong learning and the state of the art. Figure 2 shows the central aspects which were tackled within the expert interviews.

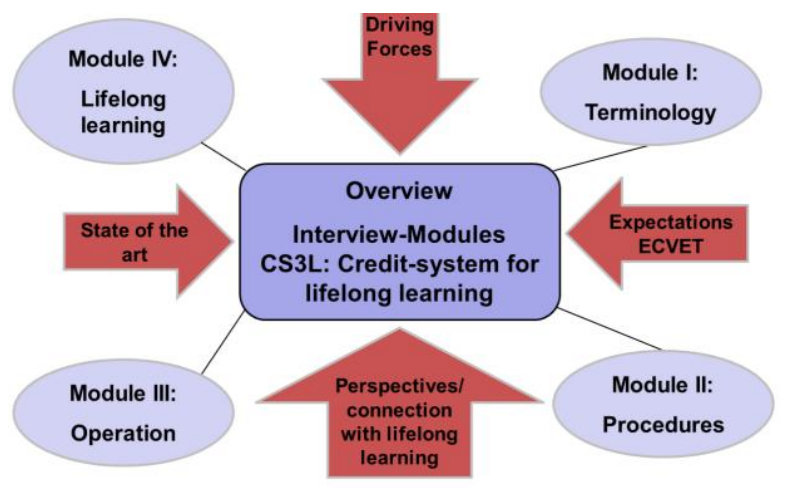

Figure 2. Modules of the interview guideline

\section{Credit systems and transfer in selected European countries}

In Scotland the providers of educational programs are usually responsible for access to and transition between them and there are few formal entry requirements. Although the Scottish Credit and Qualification Framework and the qualification portfolio awarded by the Scottish Qualification Authority are designed to provide progression sequences, which typically connect qualifications at different levels in the same field, many learners probably join at different points of the sequence. Prior qualifications, other learning and experience as well as the core skills demonstrated by the learner are likely taken into account [4: 7]. Figure 3 shows the structure and design of the SCQF. This qualification framework differentiates between 12 vertical levels as well as between different settings of learning. 


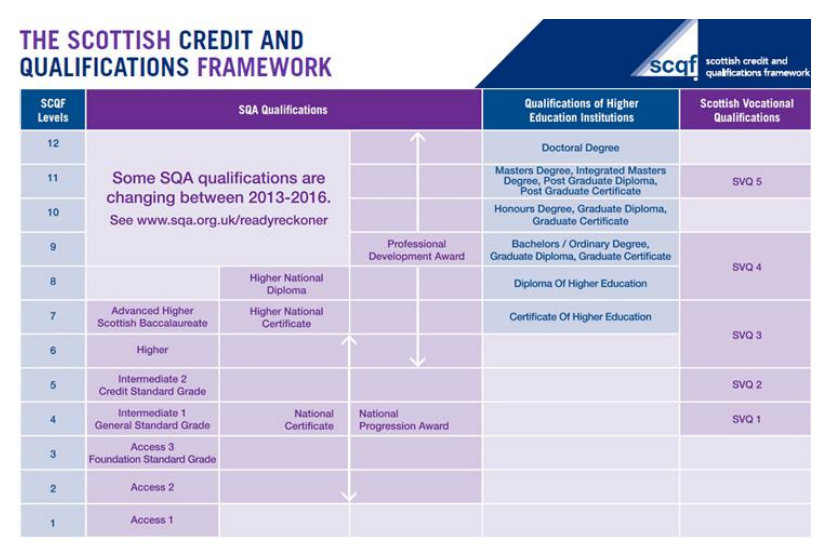

Source: www.scqf.org.uk

\section{Figure 3. Scottish Credit and Qualification Framework}

The aim of the SCQF is not only facilitating credit transfer, but also an important tool for designing and describing qualifications as well as for planning their interrelationships [4: 11; 5: 9]. In Scotland the process of development of the SCQF was connected with different desires and perceived needs: "1. raise participation and enhance progression, especially among young people, by providing more opportunities particularly for those with middle or lower levels of attainment in compulsory school 2. make VET more attractive by developing pathways within VET and from VET to general/higher education, by integrating vocational and general learning; to promote parity of esteem 3. reduce exclusion by enhancing opportunities for those at risk and recognising existing skills and prior learning on which to build 4. update VET, enhance its relevance and promote pedagogical change 5. rationalise provision and enhance the coherence and coordination of the learning system" [4: 11]. The increased focus on recognition of prior learning (RPL) also reflects all of these policy drivers, and in particular the increased importance of skills [4:13].

In contrast to many other NQFs level and credit are the two conceptual pillars of the SCQF. Including credit has significant implications for its architecture and uses. Learning outcomes in most Scottish qualifications are grouped into units. Within the SQA system, all units are accredited so that all individuals who successfully complete even a single unit are given a so called Scottish Qualifications Certificate [4: 13]. Furthermore the SCQF distinguishes between general and specific credit - respectively related to credit accumulation and credit transfer. General credit refers to a fixed volume of credit allocated to a qualification or unit. Furthermore it is the basis of credit accumulation and the design of programmes or qualifications defined in terms of credit volume. Besides credit values are used to define types of qualifications within the SCQF [4: 14f.]. Regarding RPL outcomes the SCQF distinguishes different types - not all of which result in the award of credit points. If so they may be used to gain entry to an educational programme [5: 72].

It can be summarized that in Scottish VET and education and training system in general, credit is a tool to manage learning and to design and plan programs. And this is probably more important than its use as a tool for recognition of learning or credit transfer. The system is based on credit accumulation more than on credit transfer [4: 15].

The Scottish NQF influences diverse interfaces within the educational system. The interface from prior learning into mainstream VET relates to transitions into mainstream VET at college and into work-based training in the form of so called Modern Apprenticeships. These transitions include transitions from general education into secondary schools. Furthermore they include transitions from preapprenticeship and training programmes for young people at risk of exclusion [4: 22]. In the interface within mainstream VET the Scottish focus lies on transitions between full-time VET typically delivered in colleges and work-based VET that is often delivered in Modern Apprenticeships, based on national occupational standards and certificated at least partly by competence-based SVQs. Besides these transitions between different Modern Apprenticeships and between different qualifications, especially those awarded by different bodies, have to be considered at this interface [4: 26]. In the interface from VET to higher education transitions between colleges' subdegree provision and degree-level provision (largely at university) have to be considered although the Scottish study showed that the implied labelling of college as 'vocational' and university degrees as 'non-vocational' is questionable. This interface also includes transitions between Modern Apprenticeships/SVQs and degrees [4: 30].

Overall the interface from VET to higher education is the most important one regarding credit transfer. At this interface credit transfer is most visible and understood and there most credit transfer takes place. However attention is now also directed to other possible credit transfer routes. These developments are part of creating the 'flexible, efficient learner journeys' envisaged by the governmental policy [4: 30].

The SCQF and the ECVET are based on a number of common principles. Both are based on learning outcomes and assume that outcomes will be grouped into units. Furthermore both are linked with a wider set of measures concerning qualification levels and quality assurance. Both systems are voluntary as the recognition of credit for transfer is a decision of the receiving organisation (in SCQF terminology) or the 
home institution (in the ECVET terminology). But the SCQF's distinction between general and specific credit is not reflected in the ECVET [4: 43]. In general European influences on Scottish policy and practice concerning credit in relation to VET can be characterized as marginal [4: 44].

Concluding the situation in Scotland shows kind of a paradox of the education and training system at all analysed interfaces, which may be stated as follows. On paper, Scotland has a credit-based lifelong learning system which is widely seen to be one of the most flexible in the world; but there is relatively little credit transfer to be observed, in practice [4: 16]. To explain this paradox four broad conclusions can be elaborated: The first is that a system designed on the principle of credit accumulation may support flexibility and permeability through means other than formal credit transfer. Second, a credit system on its own is weaker than the 'institutional logics' which impede permeability and flexible movement within the system. The tension between the so called intrinsic and institutional logics has been a leitmotiv of the development of credit arrangements in Scotland. The SCQF is voluntary, and education providers vary in their willingness to recognise and transfer credit at the interfaces where they operate. Third, there is insufficient agreement concerning the types of learning and the contexts between which transfer is appropriate. There are several apparent epistemological boundaries across which transfer is difficult. These are perceived to involve qualitatively different types of learning (and assessment) between which little credit transfer is possible [6; 5]. Finally, and related to this, the concept of credit, at least as it is interpreted and applied in Scotland, is still firmly anchored in the education system and especially in mainstream education. The increased use of RPL might help to narrow this gap, but so far its use is still too patchy and insufficiently associated with formal credit to have this effect [4: 45ff.].

In Denmark the political focus on setting up credit systems started in the 1990's in response to some major structural problems appearing on the labour market. These caused concerns about the VET system's limited capacity to offer low skilled workers access to qualify for more qualified jobs respectively professions and the small coherence between the VET and Higher Education System. Overall three main motives can explain the Danish quest for establishing credit systems: 1. response to globalisation, 2. lifelong learning initiatives and 3 . improvement of transnational mobility [8: 6].

Meanwhile credit systems have been established within different fields of the education system. Today in higher education it is mandatory for all education programmes to deploy the ECTS system
(Undervisningsministeriets bekendtgørelse nr. 356 og 867). As part of the implementation of the Bologna process for Higher Education, in 1999 ECTS was included as the basis of the system. Within higher education the Bologna process has had the following consequences in terms of adding procedures and processes: more outcome-orientated curricula, accreditation of all new higher education programmes and certification of the Danish qualification framework. Within IVET and adult education the so called Law of Recognition of Prior Learning (Law no.562 - 2007), which passed by the Danish parliament in 2007, is by the involved stakeholders seen as a milestone in the endeavour to promote and encourage individuals to enrol in continuing education courses. But before 2007 Denmark also has had a rather long tradition of individual competency evaluation and credit respectively for providing individual credit and validation to individual applicants. This was facilitated by clauses in the various educational orders - e.g. within the Law of Vocational and Educational Training and the Law of Adult Vocational Training. In that sense within this field there was no need for additional procedures to put the credit system in place. For the implememtation process of credit transfer systems mainly two Ministries are responsible in Denmark: the Ministry of Science, Technology and Innovation within higher education and the Ministry of Education regarding all other education programmes [8: 9f.; 13f.].

In Denmark the main educational and political motives for setting up credit award systems were the following: serving general labour market objectives to upgrade the skills of the labour force, providing the individual with the best possible conditions to build upon his/her knowledge, skills and competences, to be able to document and keep record of an individual's formal qualifications and qualifications based on prior learning. Furthermore public resources and finances should be used better within the educational sector and a fundament for a better interface between "the world of education" and "the world of work" should be established [8: 13f.; 9].

Credit transfer - in Danish "merit" - means that parts of a student's learner's previous qualification are accredited to replace a part of a new education program. Credit transfer in IVET is practiced in the way that all students or apprentices, who start at a VET school, are obliged to respectively have a right to get their competences assessed within their first two weeks of school period. Teachers at vocational schools must ensure that competence assessments focus on every student's qualifications. These assessments can lead to either exemption from specific subjects respectively modules or extra training [8: 21]. Credit transfer is also possible for adults starting on IVET. Adult workers respectively employees can be awarded transfer of 
credit when they possess relevant working place experiences and/or can document relevant training and/or have relevant courses within a specific trade and/or other relevant courses/training. Within adult education the VET schools are responsible for transfer of credits and have the authority to award exemptions from modules respectively courses. Besides this the training trade committee responsible for VET profession is in charge for awarding exemption for parts of the practical training of the whole apprentice period [8: 22].

The Danish concept for RPL - among other things departs from the principle of learning outcomes. Within this concept the individual's competences are tested and assessed in relation to the learning outcomes of a particular programme. The individual's competences should be recognised, irrespective of where and how they were acquired, but without compromising the quality/standard of the education and training qualifications. The methods used must ensure a reliable assessment to secure confidence in the outcome. Furthermore the result of the assessment should be documented by issuing a certificate, which can be done by issuing a so called 'documentation of admission', a 'documentation of competence' or a 'documentation of education'. The 'documentation of admission' can be used for basic adult education, academy profession degrees and diploma programmes. In contrast a 'documentation of competence' can be issued for all six education areas while a 'documentation of education' can be issued for all areas apart from general adult education and general upper secondary subjects [8: 22f.].

The Danish term for a person's aggregated knowledge, skills and competences is 'Realkompetence', which cannot be directly translated into English. This concept refers to prior learning and more specifically to experiences obtained in a very broad sense and it covers knowledge, skills and competences acquired in an educational as well as a working context. Figure 4 shows the Danish concept of 'Realkompetence' or the approach to recognition of prior learning [10: 24].

In Denmark the political discussion on recognition of prior learning resulted in the passing of new rules regarding this in the areas of adult and continuing education, which became effective on 1 August 2007 within the Danish Law of Recognition of Prior Learning. Before the passing of this law some educational programmes offered already for some years the awarding of individual credits for applicants. Especially adult learners had the chance to acquire exemptions for specific subjects in an educational pathway. After August 2007 more educational areas have been covered by extending the law. Hence all educational programmes respectively pathways except parts of the higher educational system are included in this law. All applicants for higher education cannot get their prior learning recognized. Instead the particular institution/university is authorized to award admission to applicants with other qualifications than the normal entry requirements [10:25].

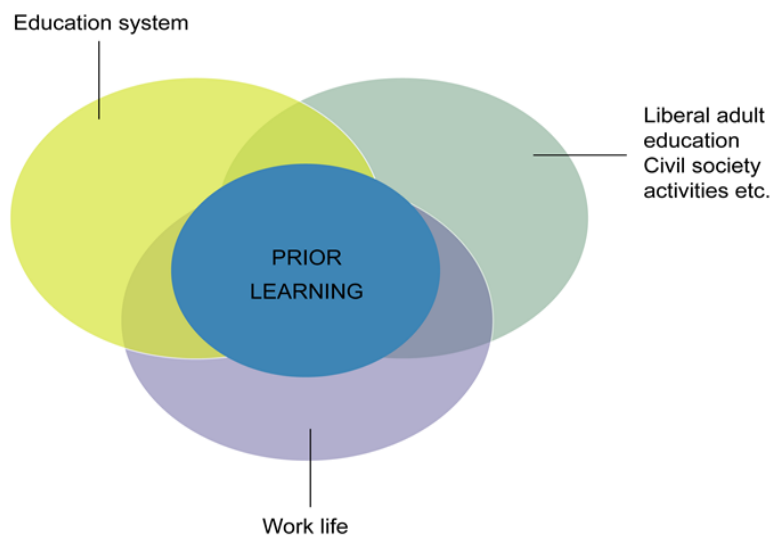

Source: Frimodt, R./ Larsen, J. O. (2010), p.25.

Figure 4. Individuals' range of knowledge, skills and competences

The European discussion and initiatives regarding credit transfer have had certain impacts on the development in Denmark - e.g. regarding the implementation of the Danish NQF. By the middle of 2010 all public recognised degrees and education and training certificates were classified in a NQF. In the area of VET, a proposal for a qualification framework with a view of supporting categorisation and enhance recognition of vocational education was prepared in 2006. Denmark decided to set up a NQF for lifelong learning parallel to the framework for further education. Consequently all eight EQF-levels will be included in the Danish framework for lifelong learning [8: 32ff.]. Other than ECTS and a NQF the ECVET implementation in Denmark is still in an embryonic phase. Most likely this will speed up when all the VET professions have finalised the NQF categorisation. So far Danish ECVET experiences have been achieved via participation in some of the many EU Leonardo ECVET pilot projects [8: 38].

Within the Netherlands learners usually need certain prior formal qualifications to enter a further qualification level in VET and in higher education. This formal entrance and access is organised for VET and higher education in different procedures. But besides this other interfaces become apparent. For different levels of VET there exist the following options: if persons are older than 16 or 18 (in most cases) entrance is possible according to adult education norms; everyone without a formal Dutch starting qualification has the right to obtain this qualification 
for free and finally people who don't have the acquired level for entering a specific programme can also turn to private funded training. For admittance to a higher education program a candidate who is 21 years or over at the start of the course and does not meet the entry requirements can take the so called $21+$ test. The aim of this test is to find out whether he has the appropriate knowledge and skills to follow the course of his choice, even though he does not have the required qualifications. This test is on the following subjects: general knowledge, Dutch language and English language [11: 12f.].

The Dutch concept just like the Danish one puts high importance on the concept of learning outcomes. In the Netherlands VET is based on a learning outcomes approach at least in theory, which is called the competence-base of VET in which all national standards embedded in VET are formulated in terms of competences. Up to now no Dutch NQF has been implemented. However there is a working group installed by the Ministry of Education, Culture and Sciences to work on setting up a National Coordination Point for translating Dutch qualifications to the EQF. The governing principles of describing, documenting and crediting prior learning is in general rather supplydominated, which means that qualifications in VET and higher education (only bachelors of professional universities) are translated into competences and for each qualification put into an procedure for accreditation of prior learning (APL). Credit transfer between qualification-programmes is officially not possible because every qualification has its own commission that constitutes the content of the qualification. Only on a restricted sectoral level or within certain domains competences from different qualifications can be transferred [11: 18f.].

In the Netherlands there are some main conceptual challenges and obstacles in putting the credit system into practice. First there is a lack regarding an assessment standard aiming at 'civil effect'. Assessment standards must meet the requirements of validity, acceptance, feasibility and functionality. Standards must be the 'property' of employer and employee. It can be regarded as an important condition to create such an open situation that the standards are made more industry-driven. Second there is a need for quality assurances of the assessment procedures. The quality of the standard can be controlled by establishing procedures for standard development and by using a programme of requirements for the design of standards or qualification structures. Furthermore the government must supervise or regulate the quality (validity, reliability and fairness) of assessment results. Third the accessibility of procedures has to be improved. Prior learning assessment procedures must be accessible to individuals and companies. Further preconditions for accessibility are the recognition and acceptance of the accreditation as well as the workability and efficiency of the system [11: 19f.].

Within the Netherlands APL-procedures underlie certain institutional framework conditions. To participate in an APL-procedure, an employee normally has to have 3 to 5 years of experience in the relevant working sector. In some collective labour agreements employees have been given the right to participate in APL. Within an APL-procedure in most cases an intake meeting respectively an interview with the employee is held first. Afterwards the candidate has the opportunity to participate in an exam-procedure for certification of qualifications. Sometimes the individual makes a portfolio in which experience is presented by a sum of certificates, notes an projects that have been worked on. Within almost all APLprocedures the examination is executed by representatives of a regional vocational training centre. Most companies try to follow the formal regulations, which are described in the Law on education and vocational training [11:25].

In the Netherlands the focus is especially put on motivating those with little or no education to participate in lifelong learning. As a consequence the process has to be as accessible and flexible as possible for individuals to facilitate finding the exact opportunity regarding their needs for continuing and further education and training [11: 25f.].

The so called polder-model is deeply anchored within the Dutch tradition. The characteristic of this model is a tripartite negotiation on national, sectoral and even on the organisational level. So harmonisation plays a decisive role in designing, implementing and innovating the Dutch society, which comprises the learning system. But laws and regulations regarding the validation of non-formal and informal learning hardly exist in the Netherlands [11:26].

Regarding the main targets connected with an APLprocedure in practice the following numbers can be discovered as more than one target is possible for each APL-procedure: $54 \%$ is used for shortening learning programmes, $51 \%$ is aiming at exemptions, $44 \%$ is looking for qualification or certification, $40 \%$ focuses on career-development and finally $12 \%$ seeks a validation of the portfolio itself [12].

Connections between existing methodologicalconceptual frameworks and current processes and initiatives at European level only exist in the present state of the art concerning credit transfer within the ECTS system and in following up the European principles and guidelines on validation of non-formal and informal learning [11: 18ff.].

In Germany most of the existing procedures for crediting prior learning are regulated on a legislative basis leading to a formal recognition within the 
education and training system. These procedures were implemented to overcome the market social selectivity of the education system and to increase educational opportunities. Furthermore an increase of employment, and hence a strengthening of the economy by easing access restrictions to higher education as well as the attainment of a higher level of qualification for employees were targeted. Existing procedures for crediting prior learning achievements within initial training are geared towards the completion of a full qualification in a state recognized training occupation. So far the formal recognition of informally gained competences is not very advanced in Germany [13: $15]$.

Furthermore in Germany different crediting and recognition procedures exist within the different fields of application. The so called final examination for externals is directed towards the completion in a staterecognised occupation. At the same time there is the opportunity of crediting full-time vocational learning towards training in the dual system. In this case the regulations are enacted by the Federal Land and the granting of credit shortens the length of in-company training. A third opportunity is the admission to the final examination for full-time vocational school leavers. In this case the Federal Land has decided which training courses at school meet the standards of the Federal Law for Vocational Education and Training (BBIG). For admission to all three opportunities the competent bodies are responsible, which means mostly the chambers. Within higher education the crediting of up to $50 \%$ of prior learning is possible. Different from the common case by casedecision, within the higher educational institutions participating in the ANKOM-project a so called blanket-recognition is possible. Regarding admission in higher education the universities are responsible. Due to the German federalism the rules for the implementation are determined in the Higher education law of the particular Federal Land. The main approach in Germany towards the accreditation of non-formal and informal learning is the ProfilPASS system. The so called ProfilPASS centres (consulting institutions) are responsible for admission, but a legal basis is still lacking for this system [13:20].

One can assume that the main driving forces for the piloting of various approaches towards crediting prior learning are triggered by the challenges described above like skills shortage and demography. The identification and recognition respectively crediting of learning are important prerequisites for an increase in the level of education in Germany. This effects the participation of the low-skilled in the labour market, their integration in jobs, the education of people with a migratory background and the number of students. Regarding these aspects the European developments and initiatives come at the right point in time as they are expected to have a strengthening effect and an orientation function in particular for domestic reform policies [13: 22].

The German government expects that the European developments result in new national opportunities regarding the modernization and flexibilization of the dual system of VET. At once, the European developments (mainly qualification frameworks and credit-systems) provoke doubts and hesitation regarding a fragmentation and weakening of the dual system. There is the fear that qualification frameworks and credit transfer systems clashes with the dual system which imparts a comprehensive range of methodological, social and personal skills [13: 26]. The insistence on the principles of the dual system and the demand for reforms regarding the implementation of a credit system for lifelong learning create a field of tension. All developed models and procedures to ease access and transition in VET have to deal with the above mentioned framework conditions. The approaches are characterised by three core features: a) by implementing the learning outcome approach into training regulations b) by crediting learning outcomes at the interfaces of the system and c) by convincing and involving the stakeholders of the various subsystems into a comprehensive strategy for lifelong learning. The activities are accompanied by the work on a NQF which has an impact on the implementation of learning outcomes and on the stakeholder's commitment [13: 27].

There are a number of approaches which are at different developmental stages and all geared to enable progression and transition among the sub-systems of education and training by crediting prior learning. Besides concrete procedures targeted to the individual and operated case-by-case (e.g. external examination, ProfilPASS system), other (more "systemic") approaches focus on establishing essential and appropriate framework conditions in order to implement concrete procedures [13: 35f.].

The opportunity of crediting up to $50 \%$ of prior learning on higher education is very little used in Germany. Individuals with vocational qualifications constitute less than $1 \%$ of all students entering higher education without the common formal qualification. The models developed within the ANKOM-project were mostly applied in the participating higher education institutions, but no details of wider dissemination or implementation are currently available. Considerably more use is being made of the authorisation to pass a regulation on credit transfer than to grant admission to a final chamber examination on completion of school-based vocational courses [13: 35f]. 
According to the REFERnet Policy Report 2009 some 1.800 people have undertaken a two-day training course in preparation to work as ProfilPASS guidance counsellors. Up to the beginning of the year 2011 around 55.000 ProfilPASS documents for adults and around 53.000 ProfilPASS documents for young people have been issued [14: 465f].

The currently available and little differentiated data on procedures connected with formal recognition indicate a comparatively low proliferation. Within the year 2010 overall 35.949 persons gained admission to the final examination as externals, $80 \%$ of them passed this exam [15]. From 2008 to 2010 the proportion of persons that have professional work experience or finished a fulltime vocational school getting admission to the final examination raise. While the percentage was $5.4 \%$ in 2009 , this rose in 2009 and 2010 to $6.4 \%$ respectively $6.3 \%[15 ; 16 ; 17]$.

\section{Results, conclusion and forecast}

In all analysed countries recognition of prior learning actually takes place. The approaches differ regarding the object of recognition (learning outcomes, competences, learning times) as well as regarding the initial point of recognition (the individual, the system, the labour market etc.). None of the approaches identified in the analysed countries conforms to the double function of accumulation and transfer similarly.

Recognition mechanisms and approaches express verbalised reform intentions and institutional logics [18]. Within the European context this manifests within the question whether recognition is primary practiced with regard to the 'educational route' (i.e. within the educational system) or with regard to the 'occupational identity' (i.e. usability on the labour market). There exist different strong fields of tension between the reform intentions and the institutional logics within the analysed countries.

The identified models and approaches are often directed towards 'access' respectively 'admission' and 'exemption', but rarely directed towards reduction of learning times.

Within all countries the legal and institutional fundamentals for recognition of learning outcomes from another learning context within another one are given. While this derives in Denmark, the Netherlands and Germany mainly from the legislation, in Scotland the National Qualification and Credit Framework forms the basis. Figure 5 shows a brief synopse of the identified national credit systems.

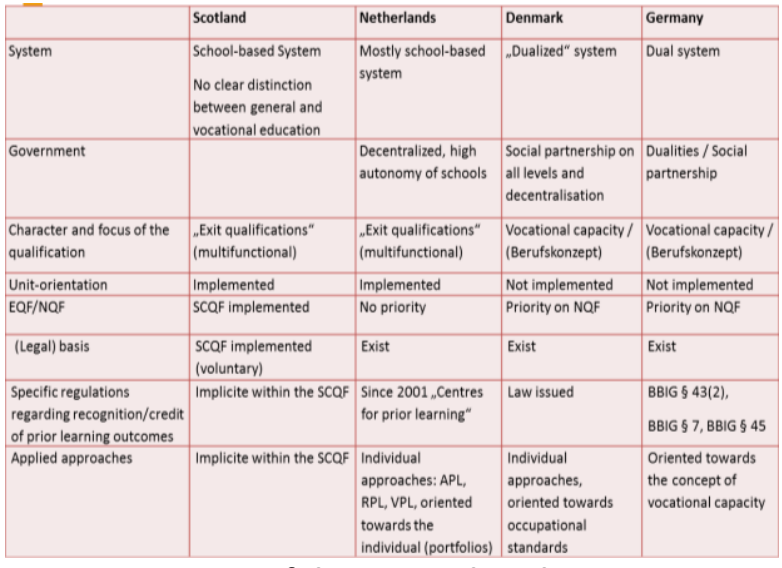

Figure 5: Synopse of the national credit systems

An inventory on existing recognition approaches in European countries and on their institutional context and a systematisation and classification of these approaches can contribute to a better understanding of permeability within the national systems. This systematisation furthermore identifies options, barriers, tension fields and necessities for regulation, which are connected with the implementation and the use of ECVET within the institutional context of the national educational systems.

While Scotland shows a certain proximity to the European instrument ECVET by orienting towards learning outcomes and the granting of credits, this is not the case for the Netherlands, Denmark and Germany. Regarding Germany one can state that the approaches on the basis of the Vocational Training Act as well as the ones within supporting initiatives are characterized by a tension field towards the European initiatives on credit-transfer.

While having a closer look at how far the national strategies and practices meet the requirements for a Europe-wide implementation of ECVET it is also important to consider how the countries evaluate the added value of this instrument - on a European level as well as on a national level. Here the results of the ECVET monitoring process provide interesting information.

These results show that the most important added value of ECVET seen by the countries in Europe is the enhancement of (cross-border) mobility (approximately 70\%). Almost half of the respondents (48\%) regard ECVET as a tool to facilitate the better alignment of qualifications with the learning outcomes approach. Furthermore transparency of qualifications $(38 \%)$ as well as permeability (33\%) are also seen as added values through the implementation of ECVET. Regarding permeability the instrument can promote mobility between different education sectors. Also the improvement of recognition and validation processes is perceived as a potential added value $(38 \%)$. About one 
quarter of the respondents attribute ECVET with a contribution to improve the quality of qualifications while $17 \%$ connect an increasing stakeholder involvement in designing qualifications with ECVET. The last aspect is realized by providing a better match between the real needs in the world of work and the provision of training and qualifications. But on the other hand the monitoring also led to the result that every fifth respondent has problems with finding clear specific added values by ECVET. These respondents are furthermore worried about the administrative burden as well as the workload linked to the instrument [19: 30]. Figure 6 gives an overview of the results of the ECVET monitoring process.

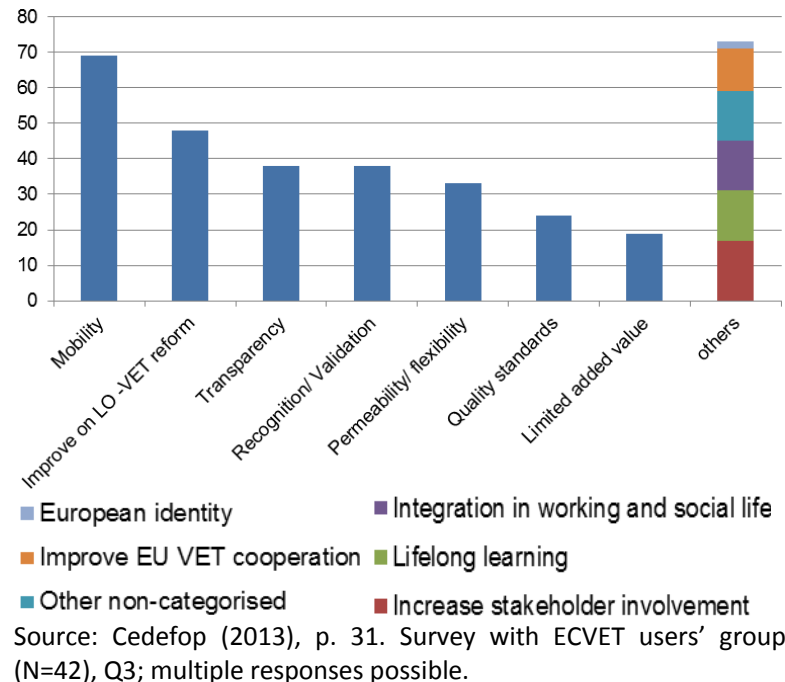

Figure 6. ECVET added value

Overall one can state that the aims connected with national credit systems are mostly coherent with the added value which the countries perceive as being connected with the implementation of ECVET. Only the focuses diverge. ECVET has a clear focus on facilitating mobility. On a national level aims like recognition/validation or permeability and transparency are more in the focus of the analyzed approaches.

It is still uncertain, if the legal and institutional fundamentals are satisfying to reach the various aims that are connected with credit systems or to promote lifelong learning. Within all analysed countries there are only insufficient data regarding the actual implementation, the de facto use and the demand for recognition approaches.

At the moment the policy implications of ECVET are regarded as follows: Although most countries are laying down the necessary foundations for ECVET, a full implementation cannot be realized in the near future. The focus of many countries is put on setting up National Qualification Frameworks and procedures for the validation and recognition of prior learning. The impact of ECVET seems to be largely limited to transnational partnerships. The relevant stakeholders associate ECVET strongly with cross-border mobility, which is not the priority in several countries [1: 4]. The four conducted country studies showed exactly the same results. Scotland uses its NQF already since a couple of time and still focuses on it. Germany as well concentrates on the development and implementation of a NQF going along with a stronger focus on the learning outcomes approach. In Denmark and especially in the Netherlands high efforts are taken to further stimulate the recognition of prior learning also going along with the orientation towards learning outcomes.

If the main function of ECVET is the enhancement of the mobility of vocational students as a transnational transfer system, its national impact remains limited. So to realize its designated contribution to the recognition of prior learning and the accumulation and transfer of credits towards qualifications, it has to be integrated into national political strategies towards the recognition of lifelong learning and the corresponding approaches in practice [1:4].

\section{References}

[1] CEDEFOP: Opportunities and challenges for ECVET, the vocational credit transfer system. Thessaloniki 2013.

[2] Education and Culture DG: ECVET. European Credit System for Vocational Education and Training.

[3] CEDEFOP: The shift to learning outcomes: policies and practices in Europe. Luxembourg 2009.

[4] Howieson, C./ Raffe, D.: Credit Systems for Lifelong Learning. Final Country Report for Scotland. Edinburgh 2012.

[5] SCQF (2009) SCQF Handbook: User Guide. Glasgow: SCQF Partnership.

[6] Raffe, D., Howieson, C. and Tinklin, T. (2007) The impact of a unified curriculum and qualifications system: the Higher Still reform of post-16 education in Scotland. British Educational Research Journal, 33, 4, 479-508.

[7] Raffe, D. (2009) Towards a dynamic model of National Qualifications Frameworks, pp. 23-42 in Allais, S., Raffe, D. and Young, M., Researching Qualifications Frameworks: some conceptual issues. Employment Working Paper No. 44. Geneva: International Labour Office.

[8] Larsen, J. O.: Credit systems for lifelong learning CS3L. Country Background. Kopenhagen 2012.

[9] Undervisningsministeriet: Danmarks strategi for livslang læring. Kopenhagen 2007. 
[10] Frimodt, R./ Larsen, J. O.: Credit systems for lifelong learning CS3L. Country Background Report. Denmark. Kopenhagen 2010.

[11] Duvekot, R./ Hanekamp, M.: Credit Systems for Lifelong Learning. Background Report Netherlands. Doentichem 2010.

[12] Dungen, M. van den (ed.), Duvekot, R., Maes, M., Pijls, T., de Reus, J. (2007). EVC op weg. Ambities, ontwikkelingen en issues. Utrecht: Kenniscentrum EVC.

[13] Eberhardt, C./ Annen, S.: Credit Systems for Lifelong Learning. Background Report Germany. Bonn 2010.

[14] Annen, S.: Anerkennung von Kompetenzen. Kriterienorientierte Analyse ausgewählter Verfahren in Europa. Bielefeld 2012.

[15] Statistisches Bundesamt: Bildung und Kultur. Berufliche Bildung (2010): Fachserie 11, Reihe 3. Wiesbaden 2011.

[16] Statistisches Bundesamt: Bildung und Kultur. Berufliche Bildung (2008): Fachserie 11, Reihe 3. Wiesbaden 2009.

[17] Statistisches Bundesamt: Bildung und Kultur. Berufliche Bildung (2009): Fachserie 11, Reihe 3. Wiesbaden 2010.

[18] Howieson, C./ Raffe, D.: Credit Systems for Lifelong Learning. Background Report Scotland. Edinburgh 2010.

[19] CEDEFOP: Monitoring ECVET implementation strategies in Europe. Working Paper No 18. Luxembourg 2013. 